\title{
Movies in Education: A Non-Formal Approach for Lifelong and Lifewide Learning
}

\section{Fabio Bocci}




\title{
Movies in Education: A Non-Formal Approach for Lifelong and Lifewide Learning
}

\author{
Fabio Bocci ${ }^{a^{*}}$ \\ ${ }^{a}$ Department of Education, Roma Tre University, Via del Castro Pretorio, 20, 00185, Rome, Italy \\ *Corresponding author: fabio.bocci@uniroma3.it
}

Abstract

Keywords: cinema; lifelong learning; cinematic experience
The cinematic language, in addition to acting as a persuasive mediator to be used in training contexts, can represent a meeting point between non-formal and formal education in the different lifelong-lifewide learning contexts. In this paper, the author specifies what we usually define as cinematic experience starting from the correlation between physical space (I'm going to the cinema) and visual act (I'm going to see a film).Then, he describes the components of the cinematic language (for example: long/full shot, plan américain/medium long shot, medium shot, medium close-up, close-up and extreme close-up, extreme wide, long/wide, etc.).Moreover, the author presents the psycho-pedagogical characteristics that are activated while participating in the viewing of a film. Finally, describes two examples of non-formal education through cinematic language. The first one refers to the Visualfest, a contest organized by the Department of Education of Roma Tre University, that aims to promote the dissemination of works created by scholars, teachers, students, educators and professionals who use images as a vector of knowledge. The second one is Co-Educa, an initiative of co-education, of alliance between the scholastic-editorial-cultural-scientific fields for the construction of a network of active subjects and the establishment of an authentic pedagogical agora.

\section{Schlüsselworte:}

filme; nicht formale

bildung; lebenslanges-

lebensbegleitendes

Lernen; Kinoerfahrung;

Filmsprache
Die filmische Sprache fungiert nicht nur als überzeugender Vermittler für Trainingskontexte, sondern auch einen Treffpunkt zwischen nicht formaler und formaler Bildung in den verschiedenen Kontexten des lebenslangen-lebensbegleitendenLernens darstellt.In diesem Artikel spezifiziert der Autor das, was wir normalerweise als Kinoerlebnis definieren, ausgehend von der Korrelation zwischen dem physischen Raum (ich gehe ins Kino) und dem visuellen Akt (ich werde einen Film sehen).Anschließend beschreibt er die Komponenten der Filmsprache (zum Beispiel: Long / Full Shot, Plan Américain / Medium Long Shot, Medium Shot, Medium Close-Up, Close-Up und Extrem-Close-Up, Extrem Wide, Long / Wide, usw).Darüber hinaus präsentiert der Autor die psychopädagogischen Eigenschaften, die bei der Betrachtung eines Films aktiviert werden. Abschließend werden zwei Beispiele für nicht formale Bildung durch Filmsprache beschrieben. Das erste bezieht sich auf das Visualfest, einen Wettbewerb, den vom Erziehungsfachbereich der Roma Tre Universität organisiert wird. Das Visualfest soll die Verbreitung von Werken fördern, die von Wissenschaftlern, Lehrern, Studenten, Pädagogen und Fachleuten erstellt wurden, die Bilder als Wissensvektor verwenden. Das zweite Beispiel ist Co-Educa, eine Initiative der Ko-Bildung, der Allianz zwischen den schulisch-redaktionellkulturwissenschaftlichen Bereichen für den Aufbau eines Netzwerks aktiver Fächer und die Schaffung einer authentischen pädagogischen Agora.

\section{Introduction}

As we know, there has been extensive study and discussion by numerous authors, in both national and international publications, of the distinction between the diverse educational paths and relationships (formal, nonformal, informal), as well as the consequent levels of education and training that follow, and the different contexts from which they arise (among the countless contributions we highlight: Simkins, 1977; du BoisReymond, 2003; Rogers, 2005; Batini 2006; Hoppers, 2006; De Camillis, 2008; Werquin, 2010; Galliani, 2012). There is a certain amount of agreement among scholars in specifying the way in which these three modes of education/instruction/learning are carried out. Formal: education takes place in an organized and structured context (a school, university or other educational institution), and is explicitly created, planned, designed and organized as a curriculum that leads to a certification (which can be of different types). Non-formal: education is connected to planned activities but not explicitly designed as learning (not provided by a training institution and not normally resulting in a certification, e.g. a day of study on a work problem in one's profession); Informal learning: multiple forms of learning through experience resulting from the activities of daily life related to work, family, or 
leisure, which are not organized or structured and do not lead to certification (e.g. membership in an association).

All of this is seen through the lens of lifelong learning, an expression that we know refers to the learning process that spans the entire arc of life (vertical, diachronic or longitudinal aspects), as well as lifewide learning, the socalled horizontal aspect of learning that refers to all areas and contexts of life.

In this light, for several years there has been an awareness of the need to overcome the conception that there are only a few places or contexts considered to be suitable for or conducive to learning (traditionally or typically schools and universities) and the need to appreciate all the experiences that individuals go through on a daily basis, through which they acquire implicit knowledge.

Given this increasingly widespread awareness, the open question that still presents a challenge for those who study and are involved in education is twofold. On the one hand, it concerns the need for the various actors in the field (educators, teachers, trainers as well as students) to know how to recognize and appreciate the innumerable opportunities that favor learning processes in the various forms in which they present themselves (or in which they break down) and above all, how to take advantage of them. On the other hand (in synergy with the first), the challenge concerns both the need and the difficulty of integrating these different ways of learning and the aspects (vertical and horizontal) that concern them. In other words, still too often formal institutions struggle to give credit to experience and knowledge gained outside of the contexts recognized as accredited (or formal). But it must also be said that there is a marked tendency (and this also applies to the business world) of many people to keep areas of their lives separate, for example, by putting what is done at work or at school in opposition to passions, hobbies and so on.

With these very brief preliminary considerations in mind, given the subject of the essay and the volume, we will deal in particular with the contribution that cinema (or, as we will shortly specify, the language of cinema) has made to the educational field as a non-formal approach that contributes to lifelong learning. Indeed, for personal interests, cinema and its language seem to be a good example and setting for reflection on an opportunity that is neither informal, non-formal nor formal.

\section{Going to the Cinema: The Cinematic Experience}

When we refer to what is commonly known as the filmmaking experience, we tend to use the term cinema in a global way, as a whole. For example, let's say I go to the cinema both to understand the physical place ( $I$ go to a movie theater) and to define the act (I go to see a film). In reality, as industry experts remind us, we are in the presence of different situations that are therefore related to different terms and concepts. We can indeed speak of Cinema, meaning it as a social fact, of Film referring to the means of recording elements of reality and, finally, of cinematic language in the sense of expressive form having its own characteristics.

Cinematic language is for the author (screenwriter, director, etc.) what sound is for the musician, and color for the painter. Those who make films are confronted with a subject and a question that are their own. It concerns the material and lexicon that characterize what later unfolds in the film narrative. Specifically, this is embodied in the concept of framing, which constitutes, as Aristarchus and Orto (1980) affirm as "the point of view from which the author films objects and people with the camera" (p. 69). As we know, these shots are conventionally distinguished by angles and fields of view.

Shots, which always have the people as their subjects (long/full shot, plan américain/medium long shot, medium shot, medium close-up, close-up and extreme close-up) are related to the real distance between the camera and the subject being filmed and the type of lens used.

Fields (extreme wide, long/wide, full, medium) include spaces and human figures, stylistically defining the space chosen by the camera (i.e. the director).

We can add a few more specific shots, such as the detail shot (a part of a person excluding the face) or the extreme close-up (a part of an object, isolated from the rest of it).

The infinite storytelling choices that the author can choose to implement through the use of cinematic language exercises an extraordinary power of attraction over the viewer, which Cesare Musatti defines as enchantment.

On the same wavelength, Edgar Morin, in a volume that has become a classic, The Cinema or The Imaginary Man (1962), talks about real magic tricks. One thinks (by identifying with the audience, what we are, mainly) of the use of framing and focus, details, time effects (time-lapse, slow-motion, flashbacks, flashforwards) or space (for example, variations from one shot to another in the same 
sequence of the location without the real geographic coordinates being respected), as well as, finally, sound (sounds, sound effects, silence, music, etc.).

The story-telling strategies of cinematic language used by the director certainly act as vectors in the construction of a certain individual and collective imagination. At the same time, and for the same reason, what happens on the screen, involves us fully, bringing us into the flow of narration and stimulating the activation of processes of and for knowledge that draws on both cognitive and affective aspects of our minds.

We enter the territory of the psychological and pedagogical implications of the use of the cinematic intermediary (and of the experience that makes it a living thing). These are the aspects that we are mainly discussing in the following paragraph.

\section{Cinema and Education: Psychopedagogical Features}

By participating in (not only watching or seeing) a cinematic story, or a film, it can (and often does) happen that we find ourselves moved in some way- cheering on a character, giving him advice or suggestions and so on. This happens, as Cesare Musatti (2000) cleverly explained, because the cinematic experience is able to activate two very powerful psychological mechanisms.

The first is the process of identification, by which we appropriate the moods of the actors and live them as if they were our own. The second is the projection process, a mechanism through which we attribute feelings, impulses and emotional states to the protagonists of the film, which are instead ours alone.

As Balàzs (1955), one of the most famous scholars of the Seventh Art, points out, "the camera guides our gaze to the place where the cinematic action takes place, the image of the film. It is as if we see everything from within, as if we are surrounded by the characters of the film" (p. 52). The emotional involvement that accompanies this experience is of particular pedagogical relevance for at least three reasons.

First of all because the emotional involvement activates in the audience two different but related ways of encountering and processing information (and therefore learning). Following the thought of Maragliano (1996) we see how one process acts by immersion (accessing knowledge in a physical way) while the other by abstraction (accessing knowledge in an analytical way). Comparing Maragliano to Bruner (1993) we can also say that during a film's viewing, the typical mechanisms of narrative thinking are activated in the viewer (emotional involvement, curiosity, and expectation orientation - this is a definition by Dieuzeide in 1966. It has to do with the emotional intensity aroused by participation in the watching of a film. A sort of state of alert (Arousal) is reached that, on the educational and training level, is particularly relevant since it affects involvement, interest, and perseverance) while the procedures and reasoning methods typical of paradigmatic thinking are then used (the explanation of personal feelings, the conscious detection of events, facts, episodes and behaviors described in the film, their identification and classification, or the analysis, the interpretation and generalization of certain observed events).

Secondly, following on the thought of Kracauer (1962), Lumbelli (1974) points out that cinema is able to "favor a perceptive restructuring of everyday reality, dismantling the conceptual schematizations through which it is trivialized and made repetitive, and in this way allowing us to perceive figural characteristics up close, aspects that we are used to letting go unnoticed" (Lumbelli, 1974, p. 21).

Thirdly and finally, the fact that the visual narratives are designed as a sort of free zone (Bocci, 2006) has great relevance to the educational field (be it informal, nonformal or formal). By reading, listening to or watching a story that does not concern us directly, but which could also concern us (through identification/projection), we experience different ways of bringing out and defining our personal belief systems, values, expectations and knowledge of specific or general situations that the film narrative brings to our attention.

We have asserted that this free zone has its place in education, making us an accurate reflection of Carboni and Cuzzolaro (1984), as we imagine education to be "a transformative experience in which the widening of cultural horizons derives not only from the learning of ideas, but from an emotional awareness that allows a link between what is known and what is felt" (p. 274). It follows that cinematic language is able to contribute to, through an affective-cognitive experience, the placing of three pedagogically relevant variables in synergistic alliance (Bocci, 2006):

a) subject matter (what comes to our attention as something that can be the object of learning); 
b) what one already knows (in general and about the subject-learning object);

c) what one feels (in relation to one's general self, to the self as a subject of knowledge in a broad sense, to the self as a subject of knowledge in that precise context and with reference to that specific subject-object of knowledge).

Operatively, it follows that one involved in this point of view (in our case, individuals who are in a non-formal learning situation) has (or gives himself) the possibility to (Bocci, 2005; 2016):

- involve one's own experiences (full of expectations, values, convictions, and so on);

- draw from one's personal strategic repertoires the creative functions belonging to their personal resources;

- encounter dynamic information conveyed by a multiplicity of cultural-symbolic systems (images, sound, gestures, etc.);

- access information in a flexible and meaningful way;

- activate a variety of degrees of involvement in the learning process (from immersion to abstraction).

All of these aspects are incorporated in the two concrete experiences that we report on in the next paragraph.

\section{Two examples of non-formal education through cinematic language}

We now present, by way of example, two education/training experiences implemented with a nonformal approach by using cinematic language. The first refers to VisualFest, an exhibition put on by the Department of Education of Roma Tre University. The second refers to CoEduca, an event organized by Edizioni del Rosone, a publisher from the city of Foggia in collaboration with several partners in the area.

\subsection{VisualFest}

VisualFest is a contest created in 2013 on the initiative of a group of scholars and experts (Roberto Cipriani, Fabio Bocci, Gianmarco Bonavolontà, Claudio Mosticone, Paolo Tomassini, Salvatore Di Riso, Mario Pireddu, Luciano Di Mele) which grew to include the participation of Valentina Domenici and Cristina Paupini starting from the 3rd year.

The exhibition, which includes feature-length, medium, and short films, aims to promote the dissemination of works created by scholars, teachers, students, educators, and professionals who use images as a vector of knowledge, as a methodology, as a method and as a medium of investigation of the phenomena that concern man in his relationship with himself and others, with the world of ideas, things, and events. This is all carried out with an openness to the different visual forms on display, in the spirit of freedom and dialogue.

The intent is, first of all, to promote the dissemination of audiovisual products created by people who use images as a tool and vehicle for research and scientific knowledge in the field of human and social disciplines in all their forms. Although there are many visual works that can be used both in the field of scientific research and in teaching, the category considered here is that in which moving images become the preferred investigative tool. For this reason, the promoters do not consider the traditional categories that generally distinguish video productions by genre and format (as well as that of the author's professional position) to be relevant, because what is primarily considered is the link existing in the work between the research (not only scientific) and the expressive choices carried out with its realization.

Secondly, the intent is to allow the public (university professors and school teachers, students, enthusiasts, etc.) to be an integral part of this process both through voting on all the works presented and through moments of debate and comparison with the authors and other invited experts.

Thirdly, finally, taking inspiration from Institutional Analysis, the intent is to give the institution (formally, the Department) the possibility of dialectising the institution (the forms of training provided within a formal context) with the instituted (presented as innovative above all because it is generated from the bottom up, by those who participate and who can find a space to contribute with know-how and awareness generated in the non-formal and informal contexts).

In summary, we can describe the peculiar characteristics of VisualFest as follows:

- it is an unconventional space within a formal context (a university department);

- it allows the direct participation of the audience (who vote on the works presented and discuss them with the authors/creators);

- it is intended for a heterogeneous audience of people with different profiles and backgrounds (teachers, students, directors, screenwriters, critics, simple enthusiasts) who have the opportunity to talk; it is therefore characterized by an attitude open to the participation of all (professionals and otherwise).

- it is guided by a spirit of research, and experimentation with creativity; 
- it also pays attention to the local community (the so-called third mission). With the term third missionattributed to the University, reference is made to the fact that the academy together with the two typical objects that characterize it (training and research) must today also work to contribute to social development. A first - and more immediate form of third mission is that which is linked to the technological transfer of products that are developed within the research projects conducted by the universities. Nevertheless, a second socio-cultural form of the third mission, which has to do with the promotion and dissemination of intellectual products, which has cultural, social, educational, civic engagement aspects as its fulcrum, has a significant value, etc ... once made available to public affairs (from the perspective of the common good) the level of well-being of society increases.

\subsection{CoEduca}

CoEduca. Education at the center of the village, is a project launched in 2016 from a joint initiative of Alain Goussot, a professor at the University of Bologna, and of the Foggia Edizioni del Rosone Publishing House. After the first year, due to the premature death of Alain Goussot, this writer and Dimitris Argiropoulos (professor at the University of Parma) have been involved.

It is an initiative of co-education, of alliance between the scholastic-editorial-cultural-scientific fields for the construction of a network of active subjects and the establishment of an authentic pedagogical agora. The events promoted by CoEduca, in fact, are among the most diverse: workshops, presentations of books, meetings with authors, film forums, debates, and more, that take place in different contexts of the city of Foggia, such as city halls, universities, schools, libraries, auditoriums, squares, etc.

These events see the involvement of numerous public figures that support and put into action the idea of Goussot of creating a permanent educational community, allowing knowledge to escape places considered as repositories, instead, hosting it and helping it become part of the community, finding a way into the city fabric, thus achieving the progressive ideal dear to Paulo Freire.

Within the various initiatives, from the very beginning a significant space was assigned to the cineforum with secondary school students, who were able to attend screenings and participate with a high degree of involvement in the resulting moments of comparison and debate. Among the films screened in recent years we mention, by way of example, their significance in terms of pedagogical analysis: La classe (Entre les murs, Laurent Cantet, 2008) andQuadrophenia (Frank Roddam, 1979).

\section{Conclusions}

In conclusion, as we read in the manifesto of the Edizioni del Rosone that accompanies the initiative, "Education focuses on the person as a subject of relationships, desires, needs, culture and rights; it connects the individual to the collective, and to the community; it proposes to educate us in a new, more communitarian way of being together". Therefore CoEduca "wants to offer an opportunity, a moment of reflection to make it clear that collaboration, solidarity, transculturality and dialogue are at the base of the construction of a more just society [...] it wants to be an opportunity, a moment of reflection to make it clear that a community pedagogy can offer the tools for creating a cooperative togetherness and can open new horizons for humanity and future generations" (http://www.edizionidelrosone.it/wordpress/?p=4564).

\section{Authors note:}

Fabio Bocci is Full Professor of Didactics and Special and Inclusive Pedagogy at the Department of Education of Roma Tre University. He coordinates the Degree Course in Primary Education, directs the Specialization Course for support teachers and is the Supervisor of the Research Laboratory for the Development of School and Social Inclusion. He is also the President of the VisualFest (a contest which aims to promote the dissemination of works created by scholars, teachers, students, educators and professionals who use images as a vector of knowledge) and the founding member of Italian Society of Special Pedagogy (SIPeS). Exponent of Disability Studies Italy, he has focused the research topics on the epistemological issues of Special Pedagogy, on teacher training, on the history of education for the disabled, on social representations of disability and diversity and on creativity. $\mathrm{He}$ is the author of 230 publications including volumes, essays and articles in national and international journals.

\section{References}

Aristarco, T. \& Orto, N. (1980). Lo schermo didattico. Un esperimento di alfabetizzazione cinematografica nella scuola dell'obbligo. Dedalo: Bari.

Balàzs, B. (1955). Il film: Evoluzione ed essenza di un'arte nuova. Torino: Einaudi.

Batini, F. (Ed.) (2006). Apprendere è un diritto. Pisa: Ets.

Bocci, F. (2005). Percorsi di analisi cinematografica per conoscere la disabilità. Difficoltà di apprendimento, 11 (2): 237-260.

Bocci, F. (2006). Post-Traumatic Stress Disorder e Cinelinguaggio. Implicazioni pedagogico-speciali in ambito educativo e formativo. Psichiatria dell'infanzia e dell'adolescenza, 2: 371-382. 
Bocci, F. (2016). Il Cinelinguaggio. Un mediatore tecnologico, trasversale a tutte le età, per analizzare i processi inclusivi a scuola e nella società. In L. Dozza \& S. Ulivieri(Eds.). L'educazione permanente a partire dalle prime età della vita a cura di. Milano: FrancoAngeli.

Bruner, J. (1993). La mente a più dimensioni. Bari: Laterz,.

Carboni, P. \& Cuzzolaro, M. (1984). La formazione degli operatori psichiatrici nei servizi pubblici. In L. Frighi (Ed.). Manuale di Igiene Mentale. Roma: Bulzoni.

De Camillis, S. (2008). Filosofia dell'apprendimento in età adulta. Viaggio nelle regioni degli apprendimenti non formali e informali. Roma: Edup.

Dieuzeide, H. (1966). Le tecniche audiovisive nell'insegnamento. Roma: Armando.

du Bois-Reymond, M. (2003). Study on the links between formal and non-formal education. Strasbourg: Council of Europe.

Galliani, L. (2012) Apprendere con le tecnologie nei contesti formali, non formali e informali. In P. Limone (Ed.). Media, tecnologie e scuola: per una nuova Cittadinanza Digitale. Bari: Progedit.
Hoppers, W. (2006). Non-formal education and basic education reform: a conceptual review. Paris: International Institute for Educational Planning

Kracauer, S. (1962). Film. Ritorno alla realtà fisica. Milano: Mondadori.

Lumbelli, L. (1974). La comunicazione filmica. Ricerche psicopedagogiche. Firenze: La Nuova Italia.

Maragliano, R. (1996). Manuale di didattica multimediale. Bari: Laterza.

Morin, E. (1962). Il cinema o dell'immaginario. Milano: Silva.

Musatti, C. (2000). Scritti sul cinema. Torino: Testo e Immagine.

Rogers, A. (2005). Non-Formal Education. Flexible Schooling or Participatory Education. New York: Springer.

Simkins, T. (1977). Non-formal Education and Development: Some Critical Issues. Manchester: Department of Adult and Higher Education.

Werquin, P. (Ed). (2010). Recognising non Formal and Informal Learning. Outcomes, Policies and Practices. Paris: OCSE.

http://www.edizionidelrosone.it/wordpress/?p=4564

(Accessed at 05.08.2020). 